\title{
CHARACTERIZATION OF DIAMOND-LIKE CARBON THIN FILMS DEPOSITED BY FACING TARGETS SPUTTERING OF GLASS-LIKE CARBON
}

\author{
Atsushi SUZUKI*, Yoichi HOSHI*, Tsutomu ISOBE** and Jack H. JUDY* \\ * The Center for Micromagnetics and Information Technologies \\ Department of Electrical Engineering, University of Minnesota \\ 200 Union Street Southeast, Minneapolis, Minnesota 55455, USA \\ **Kao Corporation, 2606, Akabane, Ichikai-machi, Haga, Tochigi, Japan
}

\begin{abstract}
In this paper we have attempted to clarify the effect of the kinetic energy of the sputtered particles on the formation of diamond-like carbon thin films using a Facing Target Sputtering System(FTS) which allows deposition of films at a very low gas pressure such as $0.2 \mathrm{~m}$ Torr. Glass-like carbon is a kind of amorphous carbon which has very small crystallites and its structure is very uniform compare to graphite. Therefore, we have also tried to evaluate the potential of glass-like carbon as sputtering targets. The optical properties of the carbon films were measured with an optical ellipsometer. The structure of the carbon films were evaluated from Raman spectroscopy. The electrical resistivity was measured using a four point probe technique. The mechanical properties were measured with a microscratch tester. The above experimental results indicate that the structure of FTS deposited carbon films changes from less amorphous to diamond-like as the argon gas pressure is decreased and their adhesion and uniformity was significantly improved. FTS carbon films about $300 \AA$ thick were also deposited on textured $\mathrm{Co}-\mathrm{Cr}-\mathrm{Ta} / \mathrm{Cr} / \mathrm{Ni}-\mathrm{P} / \mathrm{Al}$ 3.5"rigid disks for the characterization as wear resistant overcoats. The friction of the carbon films were measured using a computer-controlled constant linear velocity drag tester with a thin film head slider. The results show that the friction coefficient decreased from 0.95 to 0.45 as the argon gas pressure was decreased from $10 \mathrm{~m}$ Torr to $0.2 \mathrm{~m}$ Torr. Carbon films deposited at $0.2 \mathrm{~m}$ Torr Ar pressure show significantly lower friction and much greater durability than those deposited at $10 \mathrm{mTorr}$ Ar pressure. These results support the conclusion that FTS deposited carbon films have excellent potential as high-durability overcoats.
\end{abstract}

\section{INTRODUCTION}

Sputtered carbon thin films have been used as protective layers on thin film media because of their expected low friction and high hardness. However, the mechanical properties usually obtained by conventional DC magnetron diode sputtering are not satisfactory. In this paper we report on the properties of diamond-like carbon thin films deposited using a Facing Targets Sputtering System(FTS) with glasslike carbon targets. Glass-like carbon targets are very uniform and should prevent cone formation[1] on the surface of the targets and provide greater reproducibility than graphite targets.

\section{EXPERIMENT}

Figure 1 shows a schematic diagram of the FTS apparatus used in this experiment. Glass-like carbon targets of $10 \mathrm{~cm}$ diameter and $4 \mathrm{~mm}$ thickness in size were used. These targets were bonded to watercooled copper backing plates. The targets distance and the substrate position from the center of the targets were arranged as shown in Fig. 1. Pure argon gas were used in the sputtering gas. The sputtering gas pressure was varied from $0.2 \mathrm{mT}$ Torr to $10 \mathrm{~m}$ Torr. The discharge current was fixed to $0.5 \mathrm{~A}$ and the voltage applied to the targets was 420 to $500 \mathrm{~V}$. No substrate bias was applied. Carbon films about $5000 \AA$ thickness were deposited on silicon wafer substrates and glass plates for characterizations. The optical 


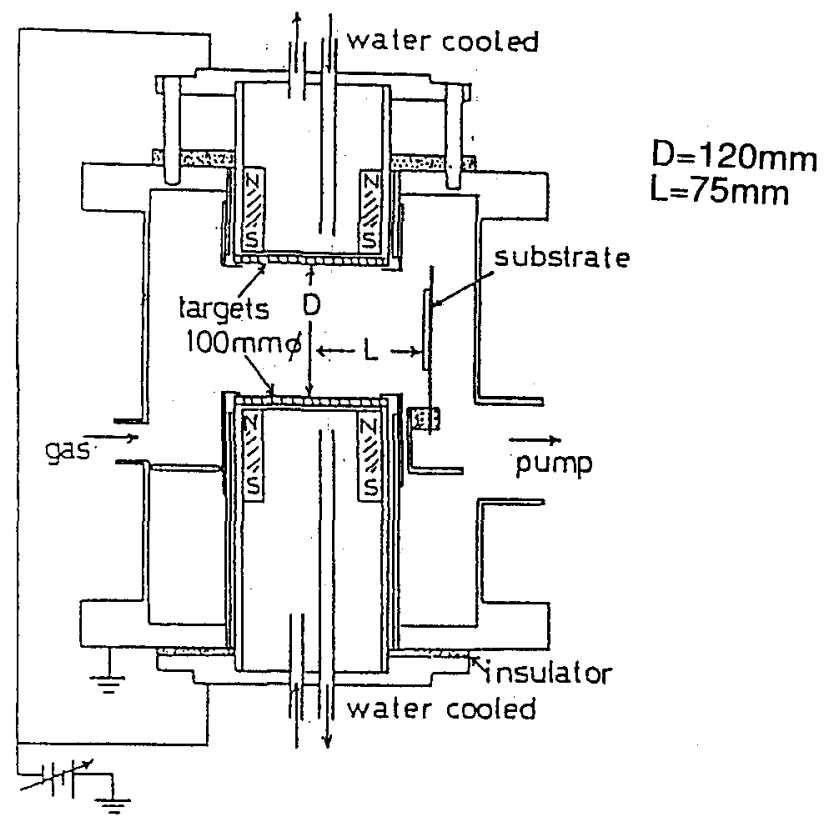

Fig.1 A schematic diagram of the Facing Targets Sputtering System

properties of the carbon films were characterized by an optical ellipsometer. The electrical resistivity was measured using a four point probe technique. The structure of the carbon films were characterized by Raman spectroscopy[2]. The surface morphology of the carbon films were characterized by scanning electron microscopy(SEM) and atomic force microscopy (AFM). The mechanical properties of the carbon films were measured with a microscratch tester[3]. Carbon films about $300 \AA$ thickness were deposited on textured $\mathrm{Co}-\mathrm{Cr}-\mathrm{Ta} / \mathrm{Cr} / \mathrm{Ni}-\mathrm{P} / \mathrm{Al} 3.5$ " rigid disks for the characterization as wear resistant overcoats. The friction of the carbon films were measured using a computer-controlled constant linear velocity drag tester using a thin film head slider. No lubrication was applied. The tribology test conditions of the drag test are shown in table I.

\section{RESULTS AND DISCUSSION}

It should be noted that sputtering can be performed successfully at argon sputtering gas pressures as low as $0.2 \mathrm{~m}$ Torr by FTS. Figure 2 shows the dependence of the refractive index(n) and extinction coefficient(k) of argon sputtering gas pressure on the carbon films. The refractive index decreased slightly as the argon sputtering gas pressure
Table I Tribology test conditions

Substrate
Carbon layer
Test mode
Head
Load
Linear velocity
Number of Passes

3.5" CoCrTa/Cr/NiP/Al 300A Dragging test Thin Film Head $12 \mathrm{~g}$ $25.5 \mathrm{~cm} / \mathrm{sec}$ 5000pass

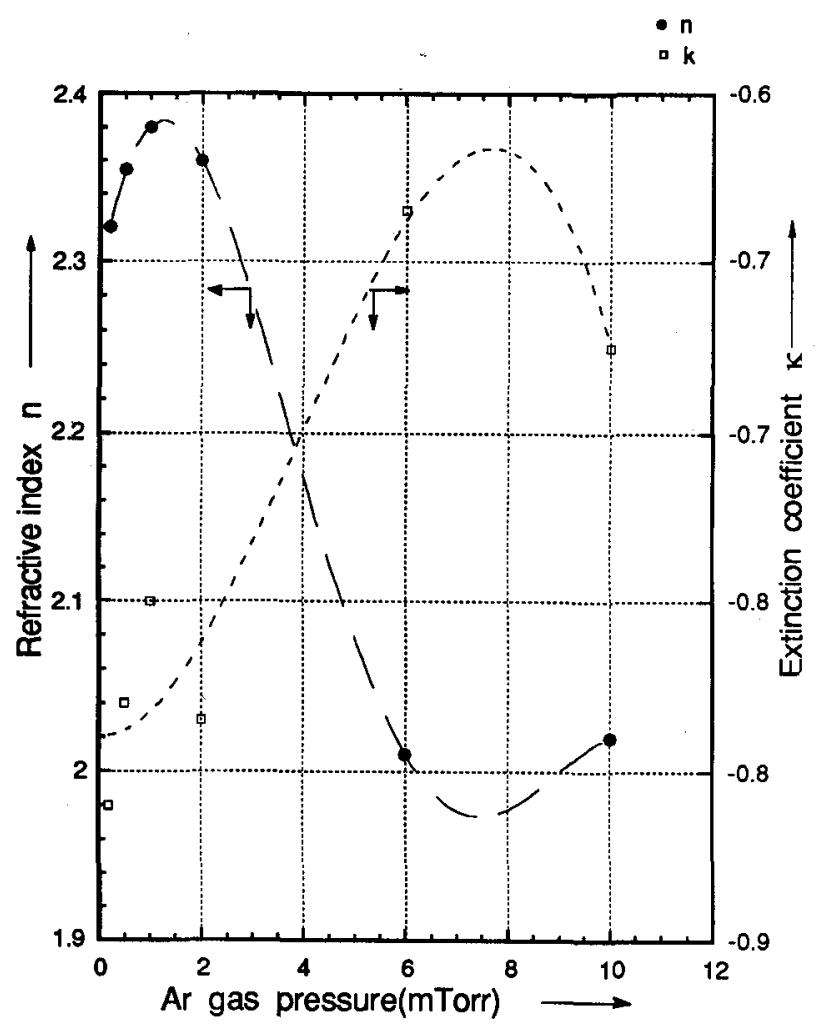

Fig. 2 Changes in optical constants n,k for sputtered carbon films at various argon sputtering gas pressure

increased above $2 \mathrm{mT}$ Torr. Since the mean free path of the sputtered particles at the argon sputtering gas pressure above $1 \mathrm{~m}$ Torr was less than the distance between the target and substrate, the decrease in the optical constant of carbon films was probably caused by the decrease in the kinetic energy of the sputtered particles incident to the substrate or the increase of the number of particles that arrive to the substrate with a large incident angle. 

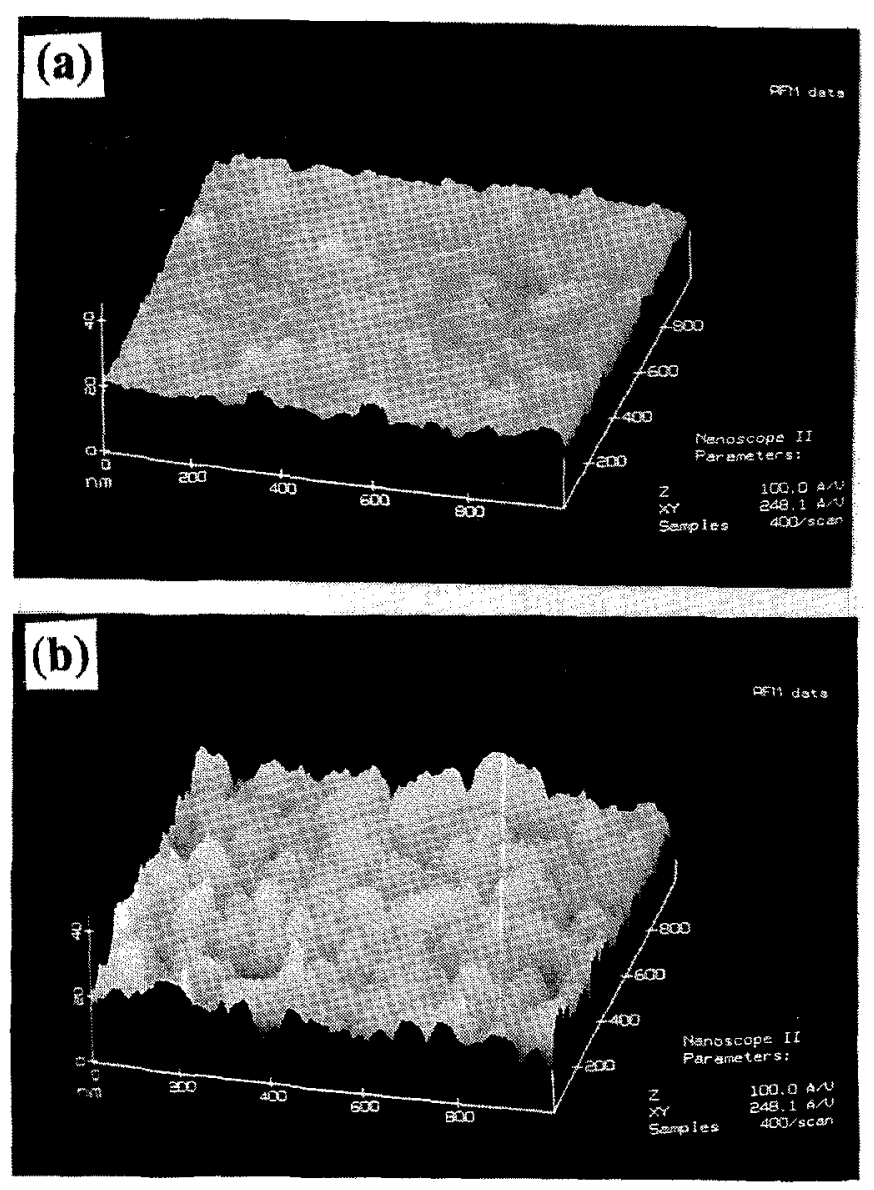

Fig. 3 AFM images of carbon films; (a) the carbon film sputtered at $0.2 \mathrm{~m}$ Torr argon sputtering gas pressure, (b) the carbon film sputtered at $10 \mathrm{mT}$ Torr argon sputtering gas pressure

Figure 3 shows the effect of argon gas pressures for the carbon film surface roughness by using AFM. The grain size of the carbon film was 50 to $100 \mathrm{~nm}$ for argon sputtering gas pressure of $0.2 \mathrm{mTorr}$. At an argon sputtering gas pressure of $10 \mathrm{mTorr}$, the grain size was increased to 100 to $150 \mathrm{~nm}$. The surface roughness of the carbon films increased from $6.4 \mathrm{~nm}$ to $14.8 \mathrm{~nm}$ as argon sputtering gas pressure increase from $0.2 \mathrm{~m}$ Torr to $10 \mathrm{mT}$ Torr. SEM observation showed that the cross section of carbon films sputtered at $0.2 \mathrm{mT}$ Torr had a very smooth structure. On the other hand, carbon films sputtered at $10 \mathrm{~m}$ Torr argon sputtering gas pressure showed columnar structure on the cross section of the films. These results suggest that the lower the argon sputtering gas pressure during the sputtering, the better the film surface roughness and uniformity.
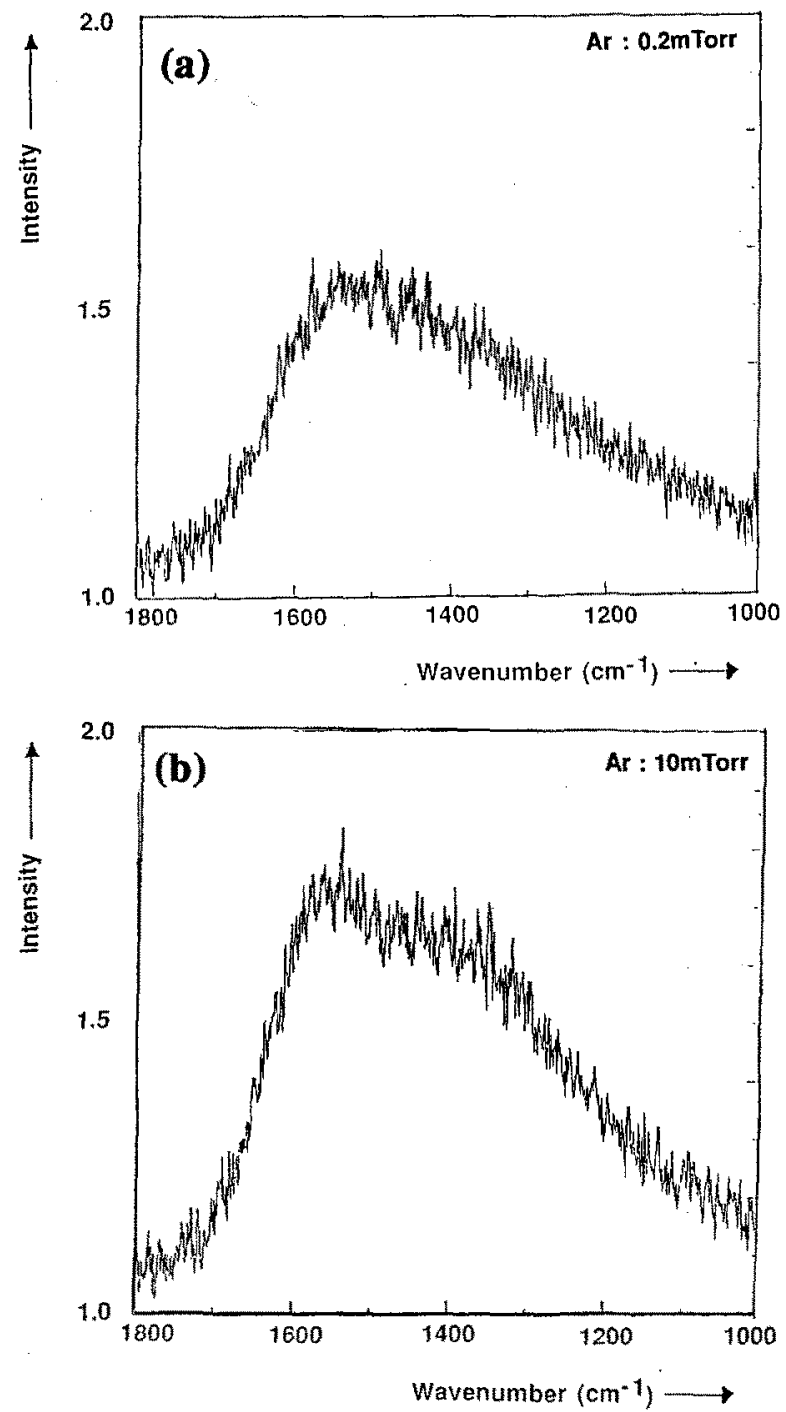

Fig. 4 Raman spectra of carbon films sputtered at (a) $0.2 \mathrm{~m}$ Torr argon sputtering gas pressure, (b) 10mTorr argon sputtering gas pressure

Figure 4 shows the effect of the argon sputtering gas pressure on the Raman shift of the carbon films. It was obvious that both carbon films are amorphous. As the argon sputtering gas pressure decreased from $10 \mathrm{~m}$ Torr to $0.2 \mathrm{mTorr}$, the band at $1350 \mathrm{~cm}^{-1}$ was weakened. Since the bands at $1350 \mathrm{~cm}^{-1}$ correspond to the interlayer shear vibration of graphitic crystalline[2], the weakened band suggest that the size of the graphitic crystalline is reduced. As the argon sputtering gas pressure was reduced from $10 \mathrm{~m}$ Torr to $0.2 \mathrm{mT}$ Torr, the structure of the carbon film 


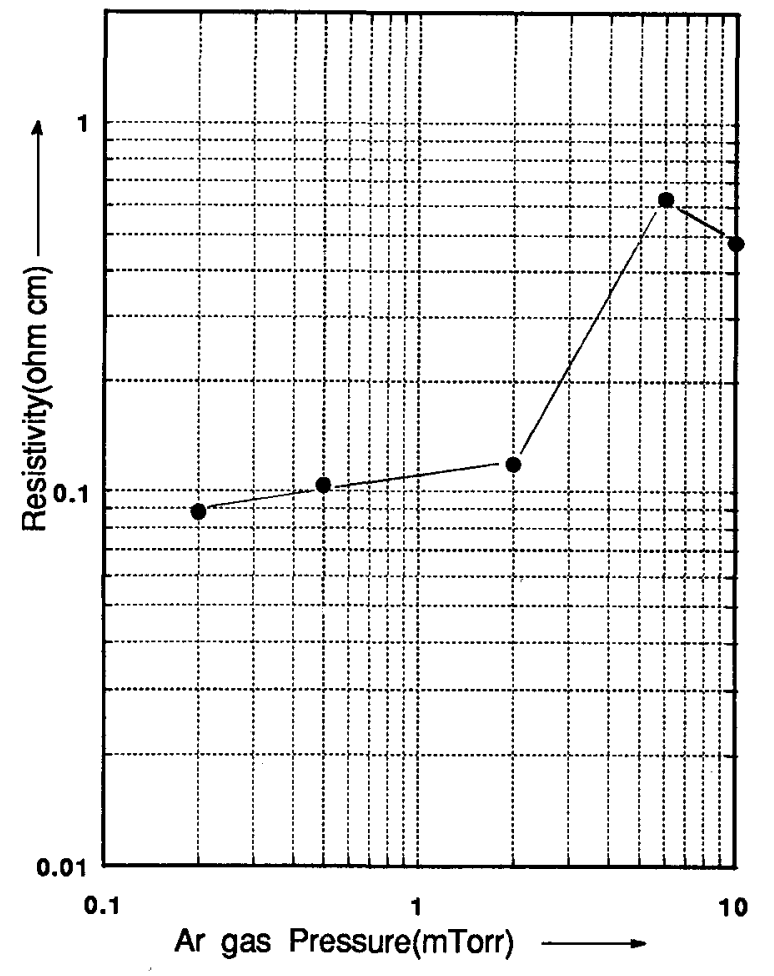

Fig. 5 Changes in resistivity for sputtered carbon films at various argon sputtering gas pressures

changed from a less amorphous carbon film, which has larger graphitic crystalline than diamond-like carbon film, to a diamond-like carbon film, which has smaller graphite crystallites and much more uniform film structure.

The resistivity of FTS deposited carbon films was found to increase from $0.09 \mathrm{ohm} \mathrm{cm}$ to $0.5 \mathrm{ohm}$ $\mathrm{cm}$ as the argon sputtering gas pressure was increased from $0.2 \mathrm{~m}$ Torr to $10 \mathrm{~m}$ Torr as shown in Fig. 5 . Because less amorphous films have lower uniformity and density compared to the diamond-like carbon, this results shows that they also have higher resistivity than diamond-like carbon film.

The adhesive force of the carbon films was determined using a microscratch tester Fig. 6 shows the dependence of the adhesive force on the argon sputtering gas pressure. The adhesive force of carbon films were improved from $0.027 \mathrm{~N}$ to $0.047 \mathrm{~N}$ as the argon sputtering gas pressure was decreased. This result suggests that the lower the argon sputtering gas pressure, the higher the kinetic energy of the sputtered

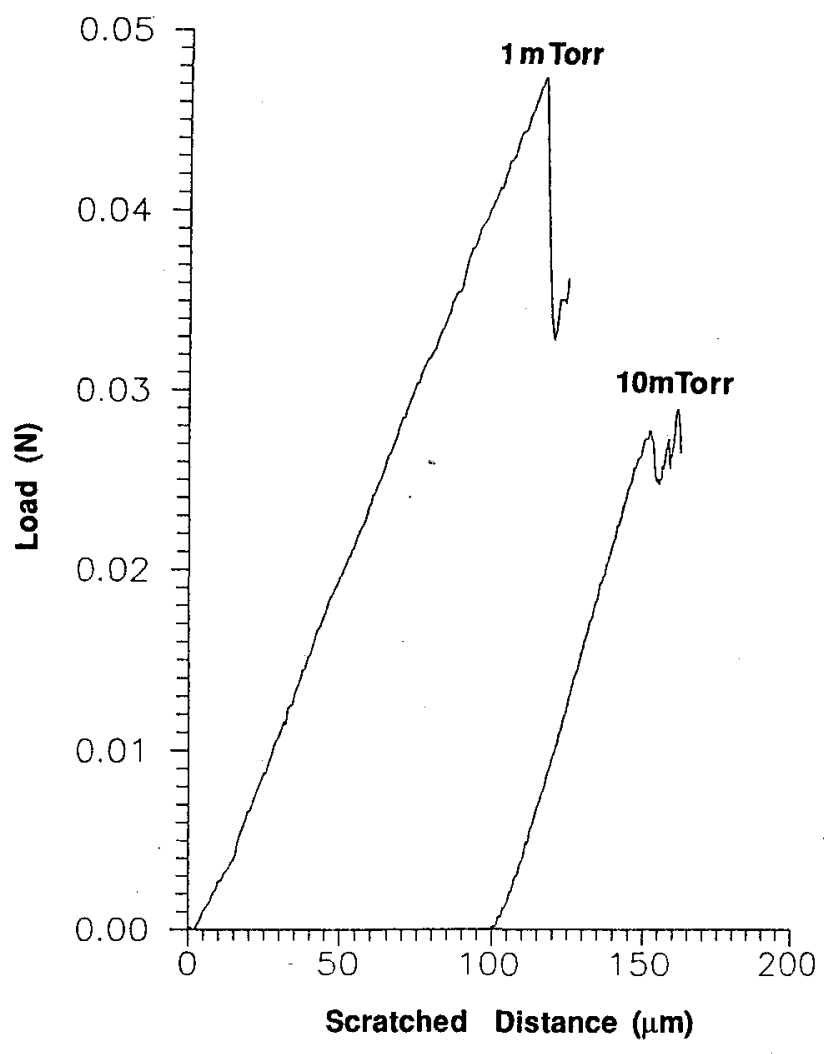

Fig. 6 Typical scratch loading curves of carbon film deposited on $\mathrm{Si}$ substrates at different argon sputtering gas pressure

carbon particles bombarding the substrate. Therefore, carbon films bombarded by high energy carbon particles show a higher adhesive force.

The dynamic friction coefficients of carbon films are shown in Fig.7. As the argon sputtering gas pressure was decreased from $10 \mathrm{~m}$ Torr to $0.2 \mathrm{mTorr}$ the friction coefficient of the carbon films decreased from 0.95 to 0.45 after a 5000 pass drag test. In the case of carbon films deposited at $10 \mathrm{mT}$ Torr argon sputtering gas pressure, the initial friction coefficient was 0.80 . During the continuous dragging test, the friction coefficient fluctuated and an increase of the friction coefficient up to 0.95 was observed. This friction coefficient increase was probably caused by the increase of the contact area between the head slider and the carbon overcoat. On the other hand, the carbon film deposited at $0.2 \mathrm{~m}$ Torr indicated a friction coefficient around $0.40-0.45$ and was very stable during the drag tests. The friction coefficient difference between these two films was probably 


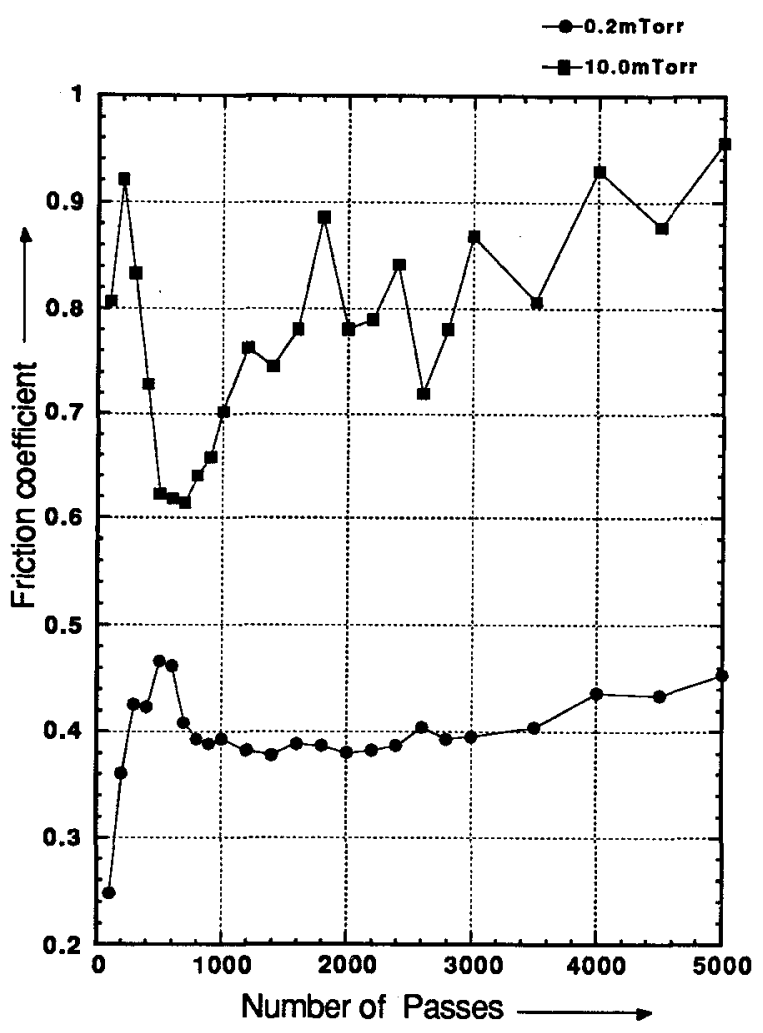

Fig.7 Typical friction coefficient curves during a 5000 pass drag test Carbon films deposited $300 \AA$ thickness on $\mathrm{CoCrTa/Cr/NiP/Al}$ textured rigid disks at different argon sputtering gas pressures

caused by the structure, uniformity, density and adhesive force difference for these carbon films. In the case of the carbon film sputtered at $10 \mathrm{mTorr}$ argon sputtering gas pressure, the film structure was less amorphous. Therefore, the structure was not as uniform as diamond-like carbon. Figure 8 shows surface profile of the two carbon films after the drag test. In the case of the carbon film deposited at $0.2 \mathrm{~m}$ Torr argon sputtering gas pressure showed less wear depth compare to the $10 \mathrm{~m}$ Torr argon sputtering gas pressure carbon film. This result correlates with the results of the microscratch test. These results support the observation that carbon films with higher uniformity and higher adhesive force not only exhibit lower friction of coefficient but also have greater durability.
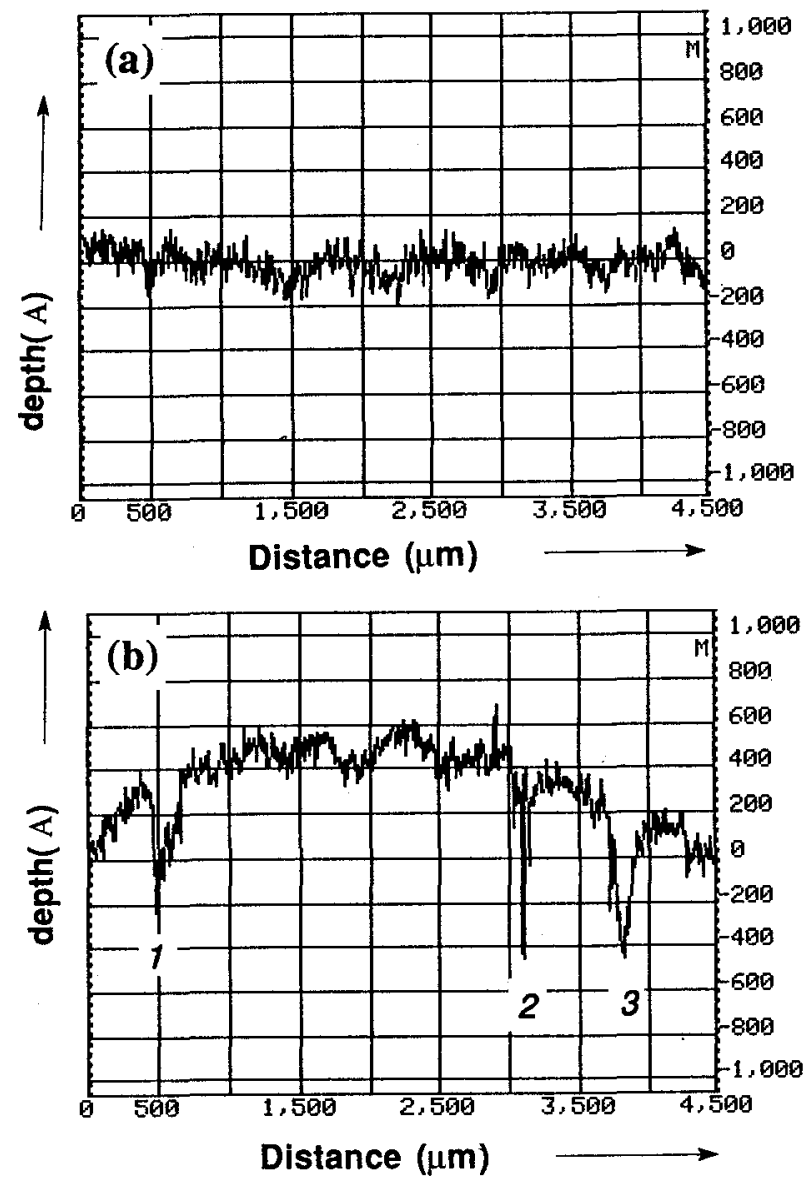

Fig. 8 Stylus profiles of worn carbon film on $\mathrm{CoCrTa/Cr/NiP/Al}$ textured rigid disks after a 5000 pass drag test The carbon films sputtered at (a) $0.2 \mathrm{mTorr}$ argon sputtering gas pressure, (b) $10 \mathrm{mT}$ Torr argon sputtering gas pressure;1,2 and 3 are wear region caused by the thin film slider rails

\section{CONCLUSION}

The effects of the kinetic energy of the deposition particles during the carbon sputtering using FTS system were investigated. In the case of the low argon sputtering gas pressure, the kinetic energy of the deposition particles have high energy. The carbon films having a diamond-like structure and also have a uniform and dense structure, a smooth surface, and good adhesion. On the other hand, carbon films deposited at high argon sputtering gas pressure showed a less amorphous carbon structure, a rough surface, and poor adhesion. In conclusion, FTS deposited diamond-like carbon films have low friction and have excellent potential as high durability overcoats. 


\section{ACKNOWLEDGEMENT}

We should like to thank Shankar Venkataraman at department of chemical engineering and material science, University of Minnesota for his assistance in microscratch measurements.

\section{REFERENCES}

[1] C.W. Chen et al.JJ. Vac. Sci. Technol.,"Surfacedefect formation in graphite targets during magnetron sputtering" A8(4),pp.3157 -3162,Jul/Aug 1990.

[2]Diane S. Knight et al.,J. Mater. Res., "Characterization of diamond films by Raman spectroscopy",Vol.4,No.2,pp.385-393,Mar/Apr1989.

[3]T.W. Wu,J. Mater. Res., "Microscratch and load relaxation tests for ultra-thin films" Vol. 6,No. 2, pp.407-426, Feb 1991. 